\title{
FEASIBILITY VALIDATION OF AN ECO-SUSTAINABLE PHOTOVOLTAIC/ENERGY STORAGE SYSTEM INTEGRATED AC TWO-PHASE TRACTION POWER SUPPLY SYSTEM OF ELECTRIFIED RAILWAY
}

\author{
WENLI DENG ${ }^{1}, \mathrm{CHAOHUA} \mathrm{DAI}^{1}, \mathrm{HANBO}_{\mathrm{ZHANG}}{ }^{2} \& \mathrm{MI} \mathrm{LI}^{1}$ \\ ${ }^{1}$ School of Electrical Engineering, Southwest Jiaotong University, China \\ ${ }^{2}$ Southwest Municipal Engineering Design and Research Institute, China
}

\begin{abstract}
With the rapid development of high-speed and heavy-haul railways around the world, how to realize energy saving and emission reduction has been a huge challenge to promote the green development of the railway system by fully utilizing existing resources (such as idle-land resources and solar energy along the railway). This paper proposes an eco-sustainable photovoltaic/energy storage system (PV/ESS) integrated into AC two-phase traction power supply system (TPSS) of electrified railway. Based on the proposed topology, a hierarchical optimization control method is also presented. Concretely, in the system layer, the energy management strategy considering triple random fluctuations (i.e., the real-time power of PV system and two-phase independent traction loads) is designed to prevent PV power flow reverse transmission and improve the utilization rate of PV energy. In the converter layer, besides the conventional maximum power point tracking (MPPT) control of boost converter, a dual-loop state-decoupling control strategy of PV inverter is adopted to ensure the effective power exchange between PV side and traction side. At the same time, the internal coordination control strategy of bidirectional DC/DC converter is detailed elaborately to enhance the long-term operational ability of ESS. Thereafter, to assess the utilization rate of PV energy and carbon emission reduction effect of TPSS under the long-time scale, the mathematical models of PV power estimation and carbon emission reduction are established, respectively. Finally, based on the typical working conditions and the measured loads/external meteorological data from a traction substation in China railway, the technical feasibility of the proposed system and hierarchical optimization control is validated.

Keywords: energy storage system, feasibility verification, photovoltaic power generation, traction power supply system, hierarchical optimization control.
\end{abstract}

\section{INTRODUCTION}

In recent years, in order to realize the energy saving and emission reduction in the field of electrified railway, more and more scholars and related departments are beginning to explore the interconnection of new energy network and transportation network [1], [2]. In especial, there are abundant solar energy resources available for exploitation along the railway [3]. However, traction power supply system (TPSS) of electrified railway is a special load of power system with randomness and volatility, especially for AC two-phase TPSS with asymmetric power supply structure, which will greatly increase the difficulty of photovoltaic (PV) access [4]. In fact, in China, there is no precedent for new energy to be connected to TPSS of more than $100,000 \mathrm{~km}$ of electrified railway lines.

On the whole, the existing extensive researches mainly focus on the non-traction field (e.g., communication systems, locomotive inspection sites, stations along the railway, etc.) [5]-[9], whereas the traction field with higher energy consumption is still in the stage of theoretical exploration and lack of systematic and in-depth research. Concretely, for AC cophase TPSS, there are already some PV engineering applications on German railways thanks to the convenience of railway-owned independent power grid [10]. However, for AC twophase TPSS, due to the particularity of power supply structure, it is difficult for conventional 
PV system to connect directly to TPSS with a transformation from three-phase (on utility grid side) and single-phase (on a power supply arm) independent operation. Additionally, most of the existing literatures only roughly evaluate the economics of new energy access [11], the technical framework of multi-energy complementary structures [12], [13], etc. The detailed analysis of connection topology, energy management and operational control of each subsystem, consumption of PV energy under long-time scale, etc., has not been carried out.

To address these issues, an eco-sustainable PV/energy storage system (ESS) is proposed to adapt the particularity of AC two-phase TPSSs in this article. In terms of control of $\mathrm{PV} / \mathrm{ESS}$, a hierarchical control architecture constituted by the system layer and the converter layer is presented. To prevent PV power flow reverse transmission and improve the utilization rate of PV energy, the comprehensive energy management strategy is elaborated in the system layer. To ensure stable and rapid dynamic performance, a dual-loop control strategy of VSC based on state decoupling, and the internal coordination control strategy of bidirectional DC/DC converter is detailed illustrated. In addition, the mathematical analysis models are established to evaluate the effect of PV energy consumption and carbon emission reduction. Finally, the technical feasibility of the proposed system and control strategy is validated, which is expected to provide some technical references for the future demonstration projects or commercial applications. Such as, the construction of intelligent traction substation, rail transit energy internet, etc.

\section{TOPOPOGY OF PV/ESS INTEGRATED AC TWO-PHASE TPSS}

Fig. 1 illustrates the topology of PV/ESS integrated AC TPSS. $110 \mathrm{kV}$ utility grid is stepped down two-phase $27.5 \mathrm{kV}$ voltage sources for $\alpha$ and $\beta$ phase feeders by $\mathrm{V} / \mathrm{v}$ traction transformer. PV/ESS is mainly composed of PV power generation unit and energy storage unit. In PV power generation unit, PV array is connected with DC/DC converter to achieve the function of boost and maximum power point tracking (MPPT), and then makes use of three-phase voltage source converter (VSC) and LC filter to implement the effective transmission of PV energy. In energy storage unit, the battery is connected onto DC-link capacitance via the bidirectional DC/DC converter. Thereafter, PV power generation unit is respectively connected with $\alpha$ and $\beta$ phase feeders by Dyn11 step-down transformer to establish a sinusoidal, symmetrical, and stable three-phase grid-connected voltage for VSC. That is, the proposed system can effectively cooperate with original TPSS supplying power for locomotives together.

In Fig. 1, $\boldsymbol{U}_{\alpha}$ and $\boldsymbol{U}_{\beta}$ are the voltages of $\alpha$ and $\beta$ phase power supply arms, respectively. $\boldsymbol{I}_{\mathrm{A}}, \boldsymbol{I}_{\mathrm{B}}$, and $\boldsymbol{I}_{\mathrm{C}}$ are the three-phase primary currents of $\mathrm{V} / \mathrm{v}$ transformer, respectively. $\boldsymbol{I}_{\alpha \mathrm{l}}$ and $\boldsymbol{I}_{\beta 1}$ are the equivalent currents of $\alpha$ and $\beta$ phase traction loads, respectively. $\boldsymbol{I}_{\alpha}$ and $\boldsymbol{I}_{\beta}$ are the equivalent currents of $\alpha$ and $\beta$ phase traction feeders, respectively. $\boldsymbol{I}_{\alpha c}$ and $\boldsymbol{I}_{\beta c}$ are the equivalent currents provided by PV system to $\alpha$ and $\beta$ phase power supply arms, respectively. $\boldsymbol{I}_{\mathrm{a}}, \boldsymbol{I}_{\mathrm{b}}$, and $\boldsymbol{I}_{\mathrm{c}}$ are the three-phase primary currents of Dyn11 step-up transformer, respectively. $U_{\text {ESS }}$ and $I_{\text {ESS }}$ are the output voltage and current of ESS, respectively. Additionally, for the sake of illustration, define the direction of currents and voltages depicted in Fig. 1 as positive direction.

\section{HIERARCHICAL OPTIMIZATION CONTROL METHOD OF PV/ESS}

\subsection{Comprehensive energy management strategy in the system layer}

In view of the fact that there is no relevant policy in railway systems of most countries to support the reverse transmission of PV power to unity grid through traction substations, some 


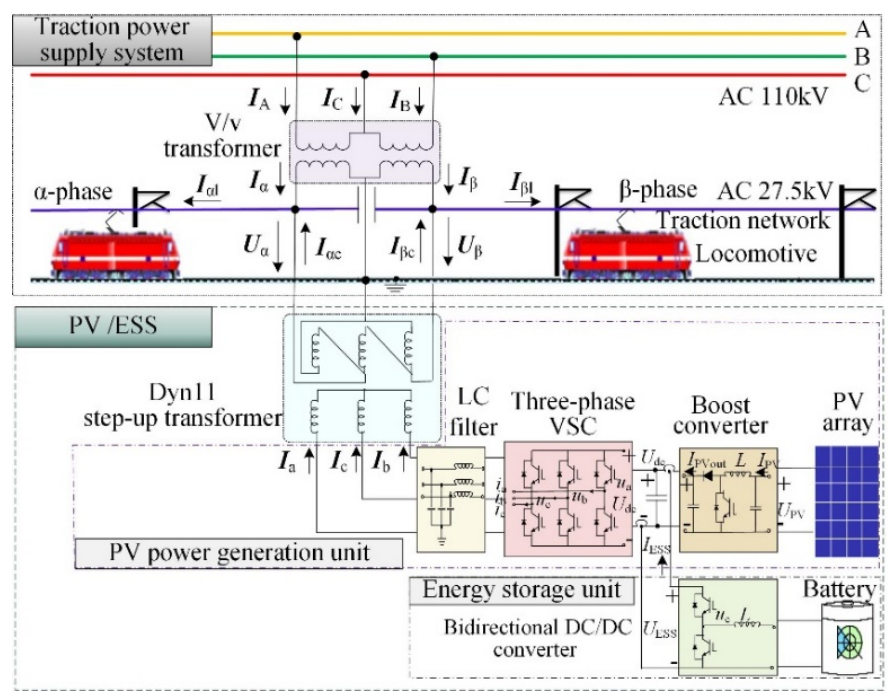

Figure 1: The topology of PV/ESS integrated AC two-phase TPSS.

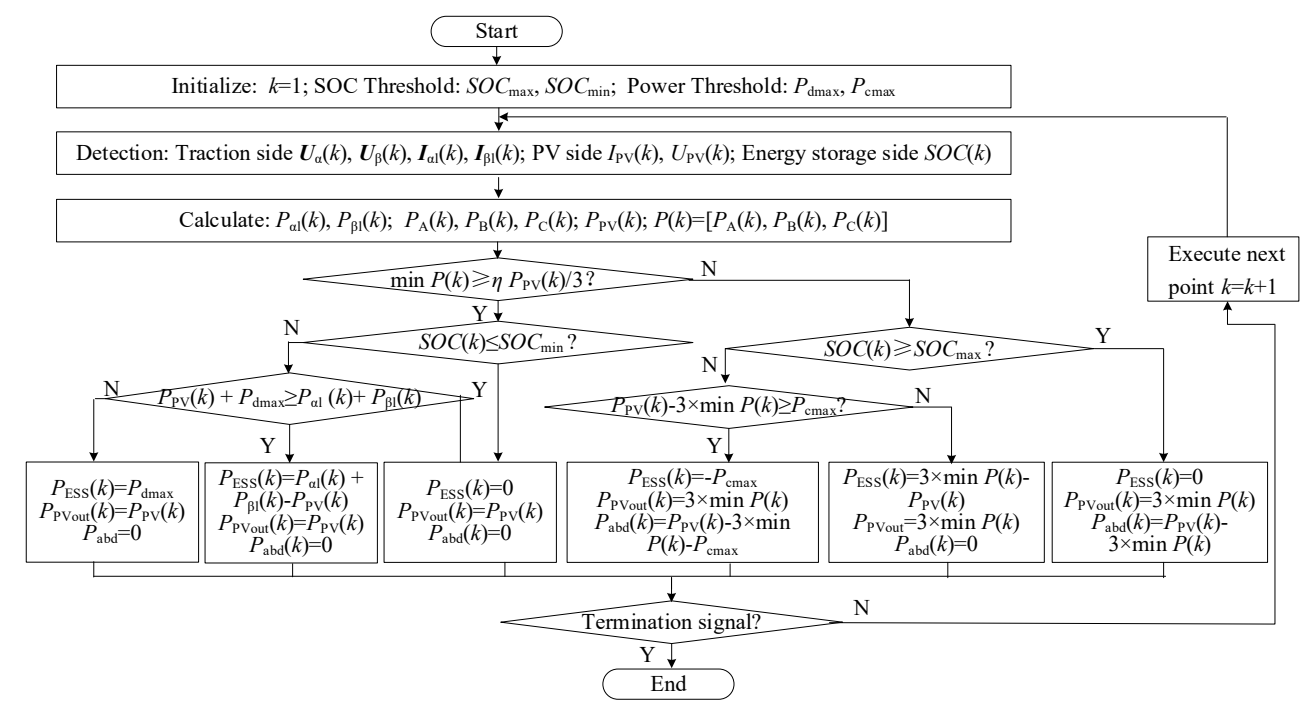

Figure 2: The flowchart of comprehensive energy management strategy of PV/ESS.

treatment measures should be adopted in application. Routinely, adopting the power-limiting control strategy can prevent the reverse transmission of PV power, however, the utilization rate of PV energy will be sacrificed. Therefore, cooperating with some ESSs to improve the utilization rate of PV energy by reasonable charging and discharging behaviour is an optionally and effectively solution.

The flowchart of comprehensive energy management strategy described in Fig. 2 shows the allocation rules of reference power instructions of PV/ESS, which incorporates the real- 
time output power of ESS $P_{\mathrm{ESS}}(k)$, external output power of PV power generation unit $P_{\text {PVout }}(k)$, unused PV power $P_{\text {abd }}(k)$. Concretely, the main steps include:

1. Initialize variables: Iterative coefficient $k$; the upper and lower limit value of SOC $S O C_{\min }, S O C_{\max }$; the maximum values of charge and discharge power $P_{\mathrm{cmax}}, P_{\mathrm{dmax}}$.

2. Detection: Real-time voltages of two power supply arms on traction side $\boldsymbol{U}_{\alpha}(k), \boldsymbol{U}_{\beta}(k)$ and currents $\boldsymbol{I}_{\alpha \mathrm{l}}(k), \boldsymbol{I}_{\beta 1}(k)$; meteorological data on PV side $S_{\text {ref }}(k), T_{\text {ref }}(k), F F(k)$; state of charge on ESS side $S O C(k)$.

3. Calculate: Active power of loads on traction side $P_{\alpha 1}(k), P_{\beta 1}(\mathrm{k})$; three-phase power on system side $P_{\mathrm{A}}(k), P_{\mathrm{B}}(k), P_{\mathrm{C}}(k)$; real-time output power on PV side $P_{\mathrm{PV}}(k)$.

4. Judge whether $P(k) \geq \eta \cdot P_{\mathrm{PV}}(k) / 3$ is satisfied: If yes, the traction loads can completely consume PV power, further judge the state of ESS, proceed to step 5. If no, PV power cannot be completely consumed, further judge the state of ESS, proceed to step 6 .

5. Judge whether $S O C(k) \leq S O C_{\min }$ is satisfied: If yes, ESS enters into standby mode $P_{\mathrm{ESS}}(k)=0$; the external output power of PV system $P_{\mathrm{PVout}}(k)=P_{\mathrm{PV}}(k)$; unused PV power $P_{\mathrm{abd}}(k)=0$. If no, ESS enters into discharge state, further judge whether $P_{\mathrm{PV}}(k)+P_{\mathrm{dmax}} \geq P_{\alpha}(k)+P_{\beta}(k)$ is satisfied: if yes, let ESS discharge at $P_{\mathrm{ESS}}(k)=P_{\alpha}(k)+P_{\beta}(k)-$ $P_{\mathrm{PV}}(k)$, external output power of $\mathrm{PV}$ system $P_{\mathrm{PVout}}(k)=P_{\mathrm{PV}}(k)$, unused $\mathrm{PV}$ power $P_{\mathrm{abd}}(k)=0$; if no, let ESS discharge at $P_{\mathrm{ESS}}(k)=P_{\mathrm{dmax}}, P_{\mathrm{PVout}}(k)=P_{\mathrm{PV}}(k), P_{\mathrm{abd}}(k)=0$.

6. Judge whether $S O C(k) \geq S O C_{\max }$ is satisfied: If yes, ESS enters into standby mode $P_{\text {ESS }}(k)=0$; the external output power of PV system $P_{\text {PVout }}(k)=3 \times \min P(k)$; unused PV power $P_{\text {abd }}(k)=P_{\mathrm{PV}}(k)-3 \times \min P(k)$. If no, ESS enters into charge state, further judge whether $P_{\mathrm{PV}}(k)-3 \times \min P(k) \geq P_{\mathrm{cmax}}$ is satisfied: if yes, let ESS charge at $P_{\mathrm{ESS}}(k)=P_{\mathrm{cmax}}$, external output power of $\mathrm{PV}$ system $P_{\mathrm{PVout}}(k)=3 \times \min P(k)$, unused $\mathrm{PV}$ power $P_{\text {abd }}(k)=P_{\mathrm{PV}}(k)-3 \times \min P(k)-P_{\text {cmax }}$; if no, let ESS charge at $P_{\mathrm{ESS}}(k)=3 \times \min P(k)-P_{\text {cmax }}$, $P_{\text {PVout }}(k)=3 \times \min P(k), P_{\text {abd }}(k)=0$.

7. Judge whether the end condition is satisfied: If yes, end the run. Otherwise, execute next point $k=k+1$, jump to step 2 .

3.2 Modeling and optimization control in the converter layer

Since DC/DC converter of PV power generation unit achieving the functions of boost and MPPT is similar to the control strategy of conventional micro-grid PV power generation system. The disturbance observation method with more engineering applications and mature technology is adopted in this paper. Consequently, this section mainly focuses on the analysis of modeling and optimization controls of VSC on PV side and bidirectional DC/DC converter on ESS side.

3.2.1 Modeling and optimization control of VSC on PV side

As the core component, VSC guarantees the safe and stable operation of PV power generation system. The topology of the adopted three-phase VSC and its control unit is shown in Fig. 3.

The mathematical model of three-phase VSC in dq coordinate system can be described as

$$
\left[\begin{array}{c}
U_{\mathrm{d}} \\
U_{\mathrm{q}}
\end{array}\right]=L \frac{d}{d t}\left[\begin{array}{c}
I_{\mathrm{d}} \\
I_{\mathrm{q}}
\end{array}\right]+R\left[\begin{array}{c}
I_{\mathrm{d}} \\
I_{\mathrm{q}}
\end{array}\right]+\omega L\left[\begin{array}{c}
-I_{\mathrm{q}} \\
I_{\mathrm{d}}
\end{array}\right]+\left[\begin{array}{c}
e_{\mathrm{d}} \\
e_{\mathrm{q}}
\end{array}\right],
$$

where $U_{\mathrm{d}}, U_{\mathrm{q}}, I_{\mathrm{d}}, I_{\mathrm{q}}$ are the dq components of VSC output voltage and current, respectively; $L$ is the filter inductor; $R$ is the line equivalent resistance; $e_{\mathrm{d}}, e_{\mathrm{q}}$ are the dq components of grid voltage, respectively. 


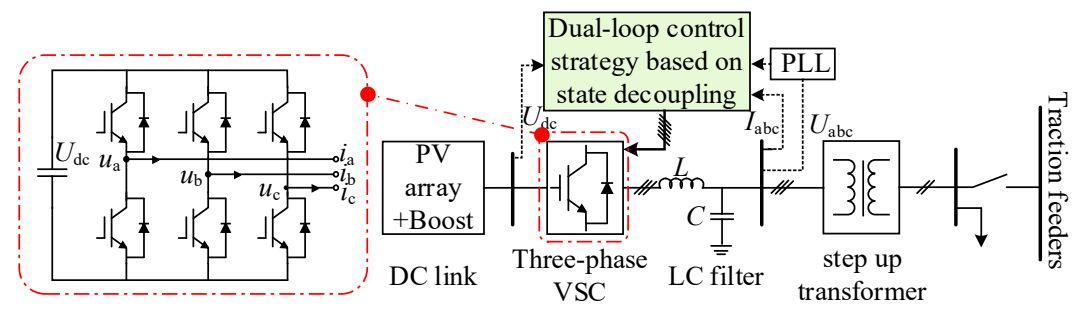

Figure 3: The topology of three-phase VSC and its control unit.

The active power $P$ and reactive power $Q$ injected into traction side through VSC can be calculated as

$$
\left\{\begin{array}{l}
P=\left(3 E I_{\mathrm{d}}\right) / 2, \\
Q=\left(3 E I_{\mathrm{q}}\right) / 2,
\end{array}\right.
$$

where $E$ is the amplitude of grid voltage synthesis vector.

Based on this, the decoupling control of input active power and reactive power can be realized through independent control of $I_{\mathrm{d}}$ and $I_{\mathrm{q}}$ in the dq synchronous rotating coordinate system. Hence, a dual-loop control strategy based on state decoupling shown in Fig. 4 is adopted to ensure the effective power exchange and establish a stable DC-link voltage, which mainly includes status detection, voltage outer loop, current inner loop, PWM generator, etc.

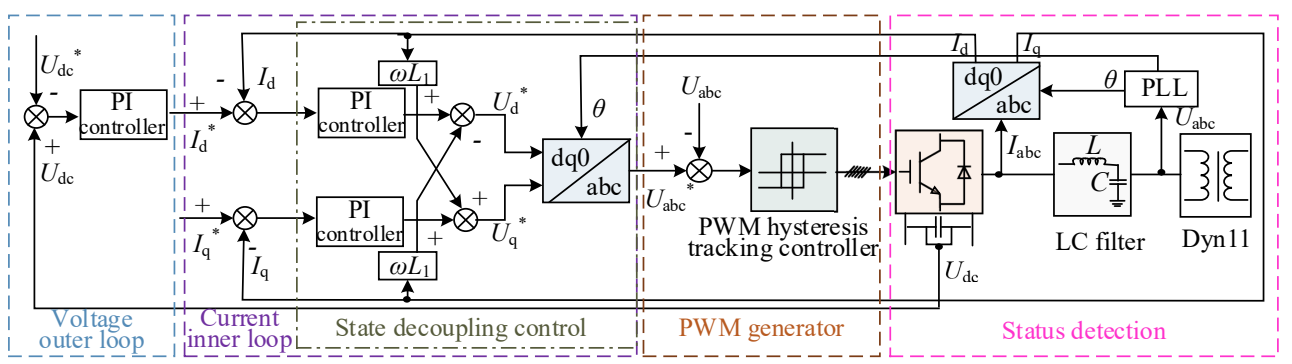

Figure 4: The principle block diagram of dual-loop state-decoupling control.

\subsubsection{Modeling and optimization control of bidirectional DC/DC converter on ESS side}

As depicted in Fig. 5(a), the bidirectional DC/DC converter is comprised of two IGBTs $S 1$ and $S 2$, two diodes $\mathrm{D}_{1}$ and $\mathrm{D}_{2}$, a filtering inductor $L$, which mainly operates in buck and boost mode. In this way, the battery can assist PV power generation unit to adjust power balance. In detail, the battery absorbs energy from DC bus by triggering $S_{1}$ in buck mode, and releases energy to DC bus to power two-phase locomotives by triggering $S_{2}$ in boost mode.

Since three-phase VSC introduced in Section 3.2.1 is mainly responsible for maintaining the stability of DC-link voltage, ESS controller adopts the control strategy of power outerloop and current inner-loop presented in Fig. 5(b), which mainly incorporates power allocation unit and charge-discharge control unit of battery. The threshold values in power allocation unit are obtained as follows 


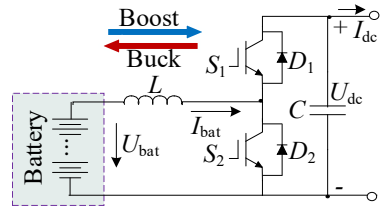

(a)

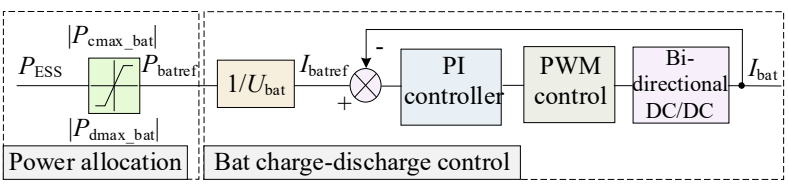

(b)

Figure 5: Principle and control block diagram of bidirectional DC/DC converter on ESS side. (a) The principle block diagram of bidirectional DC/DC converter; and (b) The principle block diagram of internal coordination control strategy.

$$
\begin{cases}P_{\text {cmax_bat }}(t)=R_{\text {c_bat }} C_{\text {a }} \operatorname{Cap}_{\text {bat }}, & \text { if } P_{\mathrm{ESS}}(t) \geq 0, \\ P_{\text {dmax_bat }}(t)=R_{\mathrm{d} \_ \text {bat }} \operatorname{Cap}_{\text {bat }}, & \text { if } P_{\mathrm{ESS}}(t)<0,\end{cases}
$$

where $R_{\text {__bat }}$ and $R_{\text {d_bat }}$ represent the maximum charging and discharge rate of battery, respectively; $C a p_{\text {bat }}$ is the rated capacity of battery.

Considering the efficiency loss of energy storage medium and converter, the charging and discharging efficiency of ESS should be considered. Set $\eta_{\mathrm{c}}$ and $\eta_{\mathrm{d}}$ represent the charging and discharging efficiency of ESS, respectively. Then, the SOC change caused by charging and discharging process can be described as

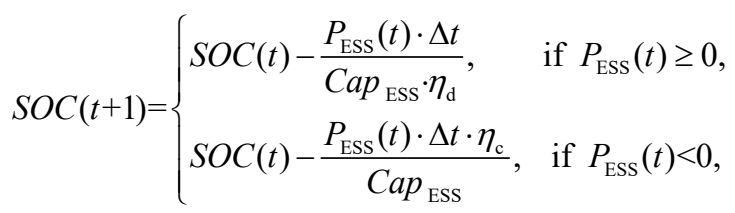

where $S O C(t)$ and $S O C(t+1)$ are the $S O C$ at time $t$ and time $t+1$, respectively; $\Delta t$ is the sampling interval.

3.3 Estimation models of PV power and carbon emission reduction under the long-time scale

\subsubsection{Estimation model of PV power}

In order to carry out large-scale and long-term case study, it is necessary to establish suitable estimation model of PV power. Obviously, the output power of PV system is affected by the surface temperature and irradiation of PV modules, while the daily irradiation, temperature, wind speed and other meteorological data are all changing in real-time. It is assumed that PV system operates normally within the estimated time period and the performance of each control unit is well. Thus, the dynamic output power of PV system can be estimated as

$$
P_{\mathrm{PV}}=\eta \cdot P_{\mathrm{STC}} \cdot \frac{S_{\mathrm{ref}}\left[1+k\left(T_{\mathrm{STC}}-T_{\mathrm{ref}}\right)\right]}{S_{\mathrm{STC}}},
$$

where $P_{\mathrm{PV}}$ is the real-time output power of PV power generation system; $P_{\mathrm{STC}}$ is the maximum output power under standard test conditions, that is, installed PV capacity; $\eta$ is the system efficiency; $k$ is the maximum power temperature coefficient of PV modules under standard test conditions; $S_{\text {ref }}$ is the surface irradiance of PV module; $T_{\text {ref }}$ is the surface temperature of PV module. 
In view of the actual situation, wind speed will indirectly affect the surface temperature of PV modules. To make the model more accurate, $T_{\text {ref }}$ can be calculated as

$$
T_{\text {ref }}=T_{\text {air }}+S_{\text {ref }} \cdot \mathrm{e}^{-3.473-0.0594 F F},
$$

where $F F$ is the wind speed near PV system; $T_{\text {air }}$ is the air temperature.

In practical application, traction loads of electrified railway will operate periodically on a daily basis according to the traffic operation chart, meanwhile PV output will be affected by annual meteorological conditions. In order to evaluate the consumption capacity of TPSS to PV system, it is necessary to combine the spatial and temporal distribution characteristics of traction loads and solar resources to investigate the overall consumption situation on an annual basis. Define $R_{\text {abd }}$ to evaluate the consumption capacity of traction loads to PV/ESS system, that is, the smaller $R_{\text {abd }}$, the stronger the consumption capacity, as follows

$$
R_{\mathrm{abd}}=\frac{E_{\mathrm{abd}}}{E_{\mathrm{PV}}} \times 100 \%=\frac{\int_{0}^{T} P_{\mathrm{abd}}(t) d t}{\int_{0}^{T} P_{\mathrm{PV}}(t) d t} \times 100 \%,
$$

where $E_{\mathrm{abd}}$ is the unused $\mathrm{PV}$ energy within the time period $T ; E_{\mathrm{PV}}$ is the total $\mathrm{PV}$ energy within the time period $T$.

\subsubsection{Estimation model of carbon emission reduction throughout the life cycle}

In order to evaluate the effect of carbon emission reduction of the proposed system throughout its life cycle, the power consumption $E_{u}$ of PV power supply chain, which covers the processes of production, transportation and waste treatment of PV system, can be calculated as

$$
E_{u}=N \sum_{1}^{n}\left(D E_{n} / c+B_{n}\right) f_{n}
$$

where $N$ is the total installed capacity of PV system; $D E_{n}$ is the direct carbon emission per unit product; $c$ is the total emission of PV system; $B_{n}$ is the amount of electricity consumed by the production unit product; $f_{n}$ is the influence factor. To simplify the calculation, according to literature [14], set $E_{u}=3786.364 N \mathrm{kWh}$.

On the other hand, with the increase of operation time, PV modules will emerge the phenomenon of power attenuation, which includes initial photoinduced attenuation, material aging attenuation and power attenuation caused by external environment or destructive factors. In this paper, the power attenuation rate of PV modules is assumed to be $3 \%$ in the first year and $0.7 \%$ per year thereafter. Assume that the operating life of PV system is 20 years. The total power $E_{\mathrm{g}}$ produced by PV system throughout its life cycle is evaluated as

$$
E_{g}=\sum_{1}^{20} m_{i} E_{\mathrm{PV}},
$$

where $m_{i}$ is the power attenuation rate of PV modules in $i$ year; $E_{\mathrm{PV}}$ is the total annual PV energy under ideal conditions.

Hence, the estimation model of carbon emission reduction throughout the life cycle is obtained as

$$
C_{\text {total }}=\left(E_{g}-E_{u}\right) C
$$


where $C_{\text {total }}$ is the total carbon emission reduction; $C$ is large power generation group unit power supply carbon dioxide emissions, where $C=550 \mathrm{~g} \mathrm{CO}_{2} / \mathrm{kWh}$.

For $E_{u}$, literature [14] already assessed that the total power consumption of $1 \mathrm{~kW} \mathrm{PV}$ system equalized $3,786.364 \mathrm{kWh}$. Based on this, this paper takes $E_{u}=3786.364 \cdot P_{\mathrm{STC}}$.

\section{SIMULATION VERIFICATION AND CASE STUDY}

\subsection{Simulation verification}

In order to verify the technical feasibility of the proposed system and hierarchical optimization control method, the simulation model of the system presented in Fig. 1 are constructed, where traction loads adopts power following control strategy, and PV installed capacity is set to $1 \mathrm{MWp}$. Table 1 lists the main simulation parameters based on a system under planning and construction in China. In detail, the parameters of TPSS comes from an actual TPSS already operated, PV modules adopts the nominal data of Suntech STP270S24 Vb, the parameters like PV installed capacity, Dyn11, battery and other modules, mainly take from system planning data and part of them provided by equipment manufacturers. Considering that PV installed capacity is small relative to traction loads, a set of small active power is respectively given to $\alpha$ and $\beta$ phase traction loads to simulate different scenarios, as

Table 1: Main simulation parameters of the system.

\begin{tabular}{|c|c|c|}
\hline Item & Parameter & Value \\
\hline \multirow{2}{*}{ Three-phase power system } & Rated voltage level & $110 \mathrm{kV}$ \\
\hline & Short circuit capacity & $750 \mathrm{MVA}$ \\
\hline \multirow{2}{*}{$\mathrm{V} / \mathrm{v}$ traction transformer } & Nominal capacity & $20 \mathrm{MVA}$ \\
\hline & Ratio of transformation & $110 / 27.5$ \\
\hline \multirow{2}{*}{ Dyn11 step-up transformer } & Nominal capacity & $1 \mathrm{MVA}$ \\
\hline & Ratio of transformation & $27.5 / 0.5$ \\
\hline \multirow{6}{*}{ PV power unit } & Installed capacity & $1 \mathrm{MWp}$ \\
\hline & PV module rated power & (STC) $270 \mathrm{Wp}$ \\
\hline & PV module short circuit current & (STC) $8.2 \mathrm{~A}$ \\
\hline & PV module open circuit voltage & (STC) $44.5 \mathrm{~V}$ \\
\hline & PV maximum power point current & (STC) $7.7 \mathrm{~A}$ \\
\hline & PV module maximum power point voltage & (STC) $35 \mathrm{~V}$ \\
\hline \multirow{3}{*}{ Three-phase VSC } & Nominal capacity & $1 \mathrm{MVA}$ \\
\hline & DC side reference voltage & $1000 \mathrm{~V}$ \\
\hline & DC-link capacitance & $20 \mathrm{mF}$ \\
\hline \multirow{2}{*}{ LC filter } & Filter inductance & $0.5 \mathrm{mH}$ \\
\hline & Filter capacitor & $120 \mathrm{pF}$ \\
\hline \multirow{5}{*}{ Battery } & Rated voltage & $750 \mathrm{~V}$ \\
\hline & Nominal capacity & $420 \mathrm{Ah}$ \\
\hline & Initial state of charge & $50 \%$ \\
\hline & Charge and discharge efficiency & $90 \%$ \\
\hline & Charge and discharge ratio & $1 \mathrm{C}$ \\
\hline \multirow{2}{*}{$\begin{array}{l}\text { Bidirectional DC/DC } \\
\text { converter }\end{array}$} & Inductance & $1 \mathrm{mH}$ \\
\hline & Capacitor & $100 \mathrm{pF}$ \\
\hline
\end{tabular}




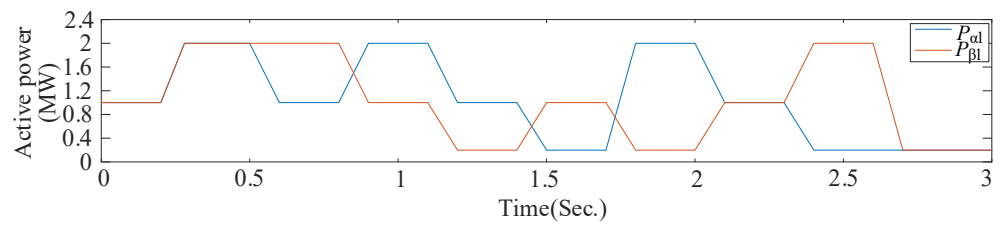

Figure 6: The given working conditions of $\alpha$ and $\beta$ phase traction loads.

shown in Fig. 6. The external working conditions of temperature and irradiance of PV system are set as standard test conditions, i.e., $S_{\mathrm{STC}}=1,000 \mathrm{~W} / \mathrm{m}^{2}, T_{\mathrm{STC}}=25^{\circ} \mathrm{C}$.

Fig. 7(a) compares and analyzes the changes of three-phase active power $P_{\mathrm{A}}, P_{\mathrm{B}}, P_{\mathrm{C}}$ on system side before and after PV/ESS access. The results show that $P_{\mathrm{A}}, P_{\mathrm{B}}$ and $P_{\mathrm{C}}$ all present a certain degree of decline after PV/ESS access, and the degree is roughly the same. Additionally, the phenomenon of reverse transmission of active power in A, B and C phase is not appeared. Combined with Fig. 7(b), It is easy to know that when two arms traction loads are small and ESS has reached the upper limit of maximum charging power, the excess PV power needs to undergo necessary power abandoning treatment (as displayed in the curve of $\left.P_{\text {abd }}\right)$ to ensure that PV power flow does not reversely transmit to $110 \mathrm{kV}$ unity grid. From the dynamic distribution curve of $P_{\text {ESS }}$ in Fig. 7(b), ESS can be conducted reasonable charging and discharging behavior based on the energy management strategy mentioned in Section 3.1. That is, the above simulation results verify the effectiveness of the proposed system and hierarchical optimization control strategy.

\subsection{Case study}

In order to evaluate the consumption capacity of TPSS to PV/ESS system, the typical daily measured load data of a traction substation in China railway is selected as shown in Fig. 8(a)

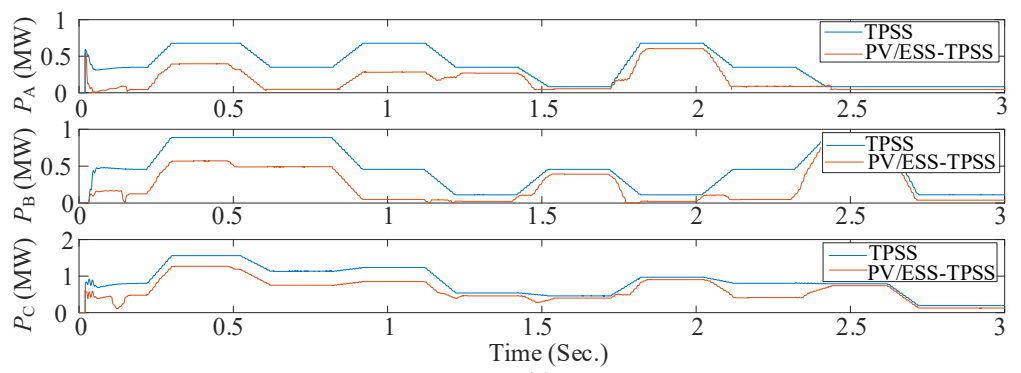

(a)

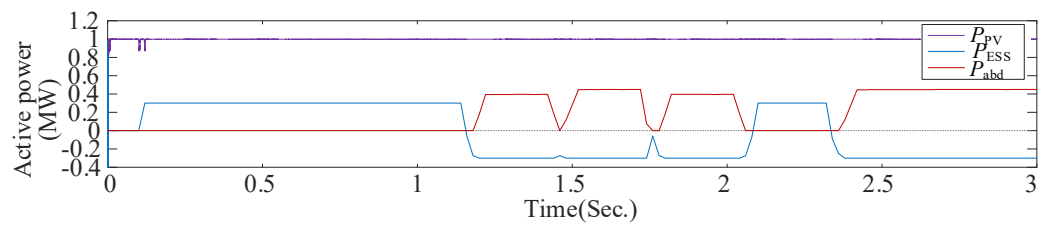

(b)

Figure 7: The results of simulation verification. (a) Three-phase active power on system side before and after PV/ESS access; and (b) Active power distribution among different subsystems. 

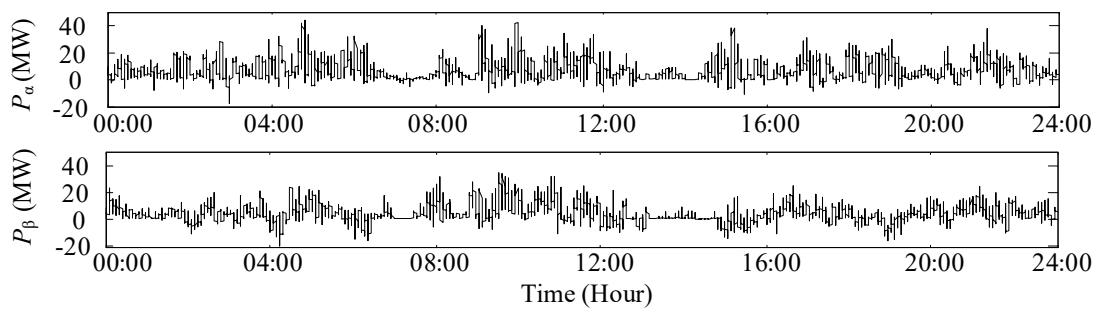

(a)

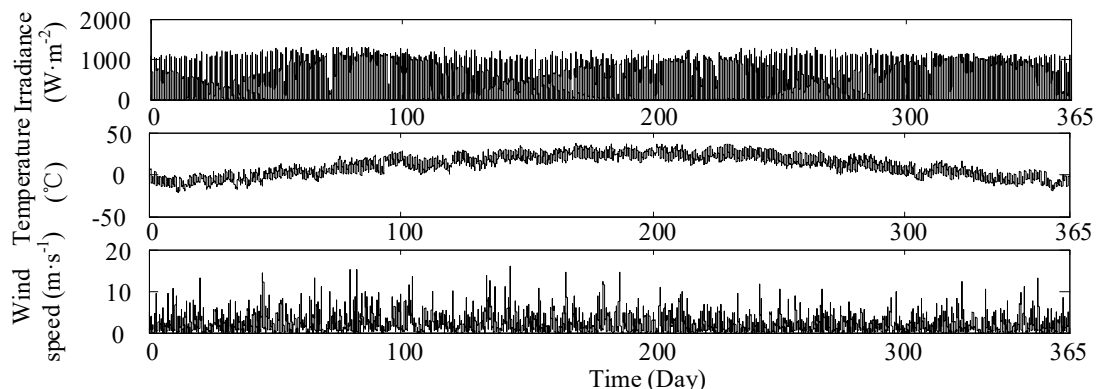

(b)

Figure 8: The measured data of case study. (a) Typical daily measured load curve of a traction substation ( $\alpha$ and $\beta$ phase); and (b) The main annual meteorological data in this area.

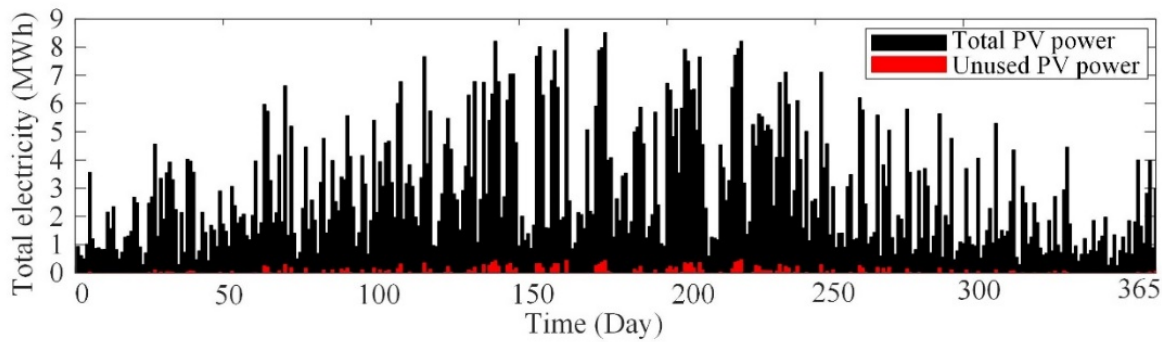

(a)

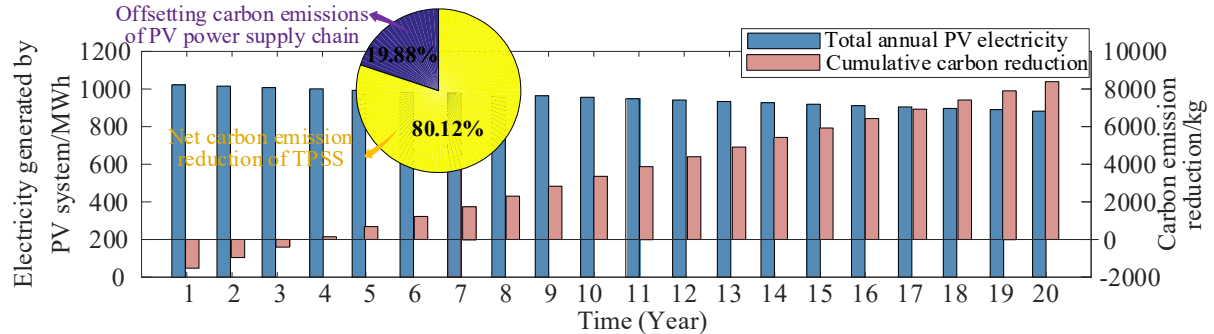

(b)

Figure 9: The results of case study. (a) Annual consumption of PV system; and (b) The annual generated electricity and carbon emission reduction over the life cycle of PV system. 
on traction side (sampling interval: $3 \mathrm{~s} /$ time), and the annual measured meteorological data in this area is also selected as shown in Fig. 8(b) on PV side (Sampling interval: 1min/ time). By means of the hierarchical optimization control method and the estimation model given in Section 3, the model of case study under long-time scale is established based on Matlab. The results of case study are illustrated in Fig. 9.

Fig. 9(a) shows the distribution of annual consumption of PV system, where statistical data indicate that the annual electricity generated by PV system is $1054.2 \mathrm{MWh}$, the annual consumption electricity of traction loads is $1,034.642 \mathrm{MWh}$, unused electricity is $19.558 \mathrm{MWh}$, and the unused rate $R_{\text {abd }}$ is $1.86 \%$. On the whole, the consumption situation of the proposed system is easily acceptable.

Fig. 9(b) shows the annual generated electricity and carbon emission reduction over the life cycle of PV system, where the life of PV system is set to 20 years. The results clearly presented that annual electricity generated by PV system is declining year by year, concretely, it is 1,054.2 MWh in the first year and 882.4 MWh in the 20th year. Additionally, statistical data also indicate that the total carbon emissions of $1 \mathrm{MW}$ PV power supply chain is $2,082.5 \mathrm{~kg} \mathrm{CO}_{2}$, which includes the processes of production, transportation and waste treatment of 1MW PV system. Based on the distribution of cumulative carbon emission reduction of TPSS, the proposed system can offset the carbon emission of PV power supply chain in the 4th year, that is, the green and low-carbon effect truly starts to carry out. After 20 years, the cumulative carbon emission reduction of TPSS reaches $8,394.5 \mathrm{~kg} \mathrm{CO}_{2}$. In detail, the carbon emission reduction of PV system in its life cycle, where $19.88 \%$ is used to offset the carbon emission of PV power supply chain, and $80.12 \%$ truly plays an environmental protection role.

\section{CONCLUSIONS}

In this paper, an eco-sustainable PV/ESS integrated AC two-phase TPSS of electrified railway is proposed, which can be used to promote the interconnection of new energy network and transportation network, and is conducive to forming a novel green development mode of TPSS. On this basis, a hierarchical optimization control method composed of the system layer and the converter layer is also presented. The system layer determines the energy transfer relationship between different subsystems and sends power instructions to corresponding controllers in different subsystems, which can be used to prevent PV power flow reverse transmission and improve the utilization rate of PV energy. In the converter layer, a dual-loop control strategy of PV inverter based on state decoupling, and the internal coordination control strategy of bidirectional DC/DC converter is designed in detail, respectively. In addition, the mathematical models of PV power estimation and carbon emission are established to assess the effect of new energy utilization and carbon emission reduction. Finally, both dynamic simulations and case study validate the technical feasibility of the proposed system and hierarchical optimization control method.

\section{ACKNOWLEDGEMENTS}

The authors would like to thank the reviewers for their helpful suggestions. This work was supported in part by the National Key Research and Development Program of China (2017YFB1201003), and Sichuan Science and Technology Program (20YYJC4428), China.

\section{REFERENCES}

[1] Khayyam, S., Ponci, F., Goikoetxea, J., Recagno, V., Bagliano, V. \& Monti, A., Railway energy management system: Centralized-decentralized automation architecture. IEEE Transactions on Smart Grid, 7(2), pp. 1164-1175, 2016. 
[2] Rifkin, J., The Third Industrial Revolution: How Lateral Power is Transforming Energy, the Economy, and the World, Palgrave Macmillan: New York, 2011.

[3] Institute of Energy Internet Innovation, Tsinghua University, 2035 report on photovoltaic development for all. www.sohu.com/a/221649580_100049846. Accessed on: 1 Feb. 2020. (In Chinese.)

[4] Li, Q.Z., Xie, S.F., Zhang, L. \& Zhang, L.Y., Electrified Railway Power Supply System and its Power Quality Control Technology, China Electric Power Press: Beijing, 2015.

[5] Jaffery, S.H.I. et al., The potential of solar powered transportation and the case for solar powered railway in Pakistan. Renewable and Sustainable Energy Reviews, 39, pp. 270-276, 2014.

[6] Morita, Y. et al., Analysis of local smoothing effect on the PV on Tokyo station. International Conference on Renewable Energy Research and Applications, IEEE, 2012.

[7] Hayashiya, H. et al., Potentials, peculiarities and prospects of solar power generation on the railway premises. International Conference on Renewable Energy Research and Applications, IEEE, 2012.

[8] Miyagawa, T. et al., Cooperative control of reactive power of distributed PV systems to suppress voltage of distribution line along railroad track. European Conference on Power Electronics and Applications, IEEE, 2015.

[9] Alam, K.S. et al., Modeling and computation of a solar-piezoelectric hybrid power plant for railway stations. International Conference on Informatics, Electronic and Vision. IEEE, pp. 155-159, 2012.

[10] Méndez-Hernández, Y. et al., Design aspects for high voltage MW PV systems for railway power supply. Proceedings of the 29th European Photovoltaic Solar Energy Conference and Exhibition, 2014.

[11] Wu, M.L., Gao, Y., Deng, W.L., Chen, H.B., Dai, C.H. \& Chen, W.R., Study of PV generation application on AC powered traction system. Proceedings of 2017 Chinese Automation Congress, IEEE, pp. 1641-1646, 2017.

[12] Dai, C.H., Deng, W.L. \& Wu, M.L., A multi-energy complementary grid connection system for electrified railway and its control method. Chinese invention patent no. CN107749637A, 2017.

[13] Aguado, J.A., Racero, A.J.S. \& de la Torre, S., Optimal operation of electric railways with renewable energy and electric storage systems. IEEE Transactions on Smart Grid, 9(2), pp. 993-1001, 2018.

[14] Guo, X.P., Lin, K., Huang, H. \& Li, Y., Carbon footprint of the photovoltaic power supply chain in China. Journal of Cleaner Production, pp. 626-633, 2019. 